Vinicius PEDRAZZI(a)

Elaine Cristina ESCOBAR ${ }^{(b)}$

José Roberto CORTELLI(c)

Alex Nogueira HAAS(d)

Ana Karina Pinto de ANDRADE(b)

Claudio Mendes PANNUTI(e)

Eliete Rodrigues de ALMEIDA ${ }^{(f)}$

Fernando Oliveira COSTA(g)

Sheila Cavalca CORTELLI(c)

Sigmar de Mello RODE ${ }^{(\mathrm{h})}$

(a) Department of Dental Materials and Prosthesis, School of Dentistry of Ribeirão Preto, Universidade de São Paulo - USP, Ribeirão Preto, SP, Brazil.

(b) Periodontology Department, School of Dentistry, Faculdades Metropolitanas Unidas - FMU, São Paulo, SP, Brazil.

(c) Periodontology Department, School of Dentistry, Universidade de Taubaté - UNITAU, Taubaté, SP, Brazil.

(d) Periodontology Department, School of Dentistry, Universidade Federal do Rio Grande do Sul - UFRGS, Rio Grande do Sul, RS, Brazil.

(e) Periodontology Department, School of Dentistry, Universidade de São Paulo - USP, São Paulo, SP, Brazil.

(f) Epidemiology and Pediatric Dentistry Department, School of Dentistry, Universidade Cruzeiro do Sul UNICSUL, São Paulo, SP, Brazil.

(g) Periodontology Department, School of Dentistry, Universidade Federal de Minas Gerais - UFMG, Belo Horizonte, MG, Brazil.

(h) Dental Materials and Prosthesis Department, Instituto de Ciência e Tecnologia - ICT, Univ Estadual Paulista - UNESP, São José dos Campos, SP, Brazil.

* Paper presented at the "Equity, Social Inclusion and Oral Health Promotion: Major Challenges" International Symposium, held at the $18^{\text {th }}$ Congress of the Brazilian Association for Oral Health Promotion (Associação Brasileira de Odontologia de Promoção de Saúde - ABOPREV), April 2013, Bauru, SP, Brazil.

Declaration of Interests: The authors certify that they have no commercial or associative interest that represents a conflict of interest inconnection with the manuscript.

Corresponding Author:

Vinicius Pedrazzi

E-mail: pedrazzi@forp.usp.br

DOI: 10.1590/1807-3107BOR-2014.vol28.0022 Epub Jun 27, 2014

Submitted: Jan 21, 2014

Accepted for publication: Apr 11, 2014

Last revision: May 29, 2014

\section{Antimicrobial mouthrinse use as an adjunct method in peri-implant biofilm control $^{*}$}

\begin{abstract}
Great possibilities for oral rehabilitation emerged as a result of scientific consolidation, as well as a large number of dental implant applications. Along with implants appeared diseases such as mucositis and peri-implantitis, requiring management through several strategies applied at different stages. Biofilm accumulation is associated with clinical signs manifest by both tooth and implant inflammation. With this in mind, regular and complete biofilm elimination becomes essential for disease prevention and host protection. Chemical control of biofilms, as an adjuvant to mechanical oral hygiene, is fully justified by its simplicity and efficacy proven by studies based on clinical evidence. The purpose of this review was to present a consensus regarding the importance of antimicrobial mouthrinse use as an auxiliary method in chemical periimplant biofilm control. The active ingredients of the several available mouthrinses include bis-biguanide, essential oils, phenols, quaternary ammonium compounds, oxygenating compounds, chlorine derivatives, plant extracts, fluorides, antibiotics and antimicrobial agent combinations. It was concluded that there is strong clinical evidence that at least two mouthrinses have scientifically proven efficacy against different oral biofilms, i.e., chlorhexidine digluconate and essential oils; however, $0.12 \%$ chlorhexidine digluconate presents a number of unwanted side effects and should be prescribed with caution. Chemical agents seem beneficial in controlling peri-implant inflammation, although they require further investigation. We recommend a scientifically proven antiseptic, with significant short and long term efficacy and with no unwanted side effects, for the prevention and/or treatment of peri-implant disease.
\end{abstract}

Keywords: Mouthwashes; Biofilms; Peri-Implantitis; Mucositis; Dental Implants.

\section{Introduction}

Aiming at controlling dental caries and periodontal disease (two of the most prevalent diseases in the world population) and also maintaining fresh and enjoyable breath, dental clinical routine should include several steps, such as detailed anamnesis, clinical examination, image analysis, moldings, treatment plan, and oral hygiene instructions. With the scientific consolidation of implant dentistry and the widespread use of dental implant applications, new and great possibilities for oral rehabilitation are emerging. However, the advent of implants has also brought 
new diseases, such as peri-implant mucositis and peri-implantitis, ${ }^{1}$ whose management also requires several strategies applied at different stages.

The indication for using mouthrinses has become customary in the last decades, usually following mechanical means for biofilm control. Chemical control of different biofilms present in the oral environment is fully justified by its simplicity and efficacy, proven by evidence from clinical studies.

Therefore, the purpose of this paper was to present a consensus regarding the importance of antimicrobial mouthrinses as an adjuvant method for the chemical control of peri-implant biofilm.

\section{Dental and peri-implant biofilm}

Biofilm is a bacteria-structured aggregate that forms on hard surfaces, in the presence of fluids. ${ }^{2}$ In the oral cavity, biofilm formation occurs on both teeth and implant surfaces. ${ }^{3}$ This aggregate is composed of bacterial microcolonies, which are considered independent communities that communicate dynamically via water channels that allow the passage of nutrients and other chemicals. ${ }^{4}$ The presence of biofilm on both tooth and implant surfaces initiates an immune-inflammatory response in local tissue and may lead to an inflammatory process in gums (gingivitis) or peri-implant mucosa (peri-implant mucositis). Failure to control biofilm over time may promote inflammatory process progression, with consequent destruction of supporting structures around the teeth (periodontitis) or destruction of bone around implants (peri-implantitis). ${ }^{3}$

Regarding microbiological aspects, there are some similarities and differences between teeth and implant biofilms. Botero et al. ${ }^{5}$ compared the subgingival microbiota around implants and teeth and reported a positive correlation for gram-negative species between periodontal and peri-implant sites. Using qualitative techniques for periodontal pathogen detection, Cortelli et al. ${ }^{6}$ compared bacterial frequencies between equivalent periodontal and peri-implant conditions, namely, periodontal or peri-implant health, peri-implant mucositis or gingivitis, and periodontitis or peri-implantitis. Results showed that bacterial frequency increased from a healthy condition to an irreversible diseased condi- tion in both teeth and implants. Porphyromonas gingivalis and Aggregatibacter actinomycetemcomitans frequencies were similar between periodontitis and peri-implantitis. Despite differences related to periodontal pathogen occurrence, there are also differences between periodontitis biofilm and that related to peri-implantitis. Peri-implantitis biofilm consists of a more complex microbiota than that observed in periodontitis. ${ }^{7}$ In peri-implant biofilm, bacterial communities were identified belonging to the genera Butyviribrio, Campylobacter, Eubacterium, Prevotella, Selenomonas, Streptococcus, Actinomyces, Leptotrichia, Propionibacterium, Peptococcus, Campylobacter and Treponema, ${ }^{8}$ whereas some of these were not observed on dental biofilm.

Koyanagi et al. ${ }^{9}$ also reported higher microbial diversity in peri-implantitis. Additionally, the Staphylococcus aureus species has been identified as relevant in early peri-implantitis, unlike periodontitis. ${ }^{10}$

In addition to the differences between teeth and implant surface biofilm, there may also exist differences in the composition of the biofilm present on different implant surfaces. ${ }^{11,12}$

\section{Peri-implant mucositis and peri- implantitis}

Peri-implant mucositis experimental studies have shown that biofilm accumulation on the peri-implant surface may induce an inflammatory response in the mucosa around the implant. ${ }^{1,13}$ Although clinical parameters did not differ between experimental gingivitis and experimental peri-implant mucositis in the Pontoriero et al. ${ }^{1}$ study, a more recent comparative study of peri-implant mucositis and gingivitis in humans reported that an immune-inflammatory response was more intense around implants than in teeth. ${ }^{13}$ The authors observed a greater increase in matrix metalloproteinase 8 (MMP-8) and interleukin-1 $\beta$ (IL-1 $\beta$ ) in the crevicular fluid from implants, as compared with that from teeth, throughout a 6 week experimental period..$^{13}$

When considering peri-implant mucositis progression, in vivo study design limitations leave some questions unanswered. A study in dogs evaluated the progression of induced periodontal and peri-implant diseases, and its authors observed more pronounced 
bone loss around implants than around teeth. ${ }^{14}$

According to a literature review, peri-implantitis affects about $10 \%$ of implants and $20 \%$ of patients about 5 to 10 years after implant placement. Factors such as smoking are associated with higher disease rates. ${ }^{15}$ Additionally, previous periodontal disease history negatively influences peri-implant disease occurrence, ${ }^{16}$ suggesting that preventive measures should be implemented before implant placement. According to Costa et al., ${ }^{17}$ preventive measures could also influence the peri-implant condition over time. Among these measures, proper intra-oral biofilm control is paramount, since under similar levels of supragingival biofilm build-up, Abreu et al. ${ }^{18}$ reported greater annual bone loss for implants than for teeth.

\section{Mechanical methods of controlling biofilm on the implant surface \\ Mechanical biofilm control}

Supra/subgingival biofilm elimination is considered the main way of reducing most oral pathologies, especially dental caries and periodontal diseases. ${ }^{19,20}$ Similarly, peri-implant mucositis and peri-implantitis treatments should consider mechanical and chemical peri-implant biofilm control and calculus removal on the implant surface, often achievable only by surgical means. ${ }^{21,22,23}$ Preventive office visits to record clinical parameters and conduct radiographic follow-up allow early peri-implantitis diagnosis, thus promoting higher implant longevity. ${ }^{3,24,25,9}$ However, it should be noted that non-surgical treatment can be effective for periimplant mucositis treatment, although this has not been observed for peri-implantitis. Several surgical treatments have shown promising results for periimplantitis; however, most published studies on peri-implant diseases are case reports or case series with an undeniable bias in data interpreting. Many studies address several therapeutic and complex procedures, making them difficult to interpret. We have also observed few comparative studies or randomized clinical trials showing the best treatment options for peri-implant diseases, thus providing little evidence to establish a definitive treatment protocol.
In addition to professional biofilm control, home oral care hygiene measures are widely known to be essential to maintaining oral health. Despite the central role of proper toothbrush use, ${ }^{26}$ tooth brushing has not proved effective enough to maintain good hygiene especially in difficult-to-reach areas, such as interproximal areas. ${ }^{27}$

There are several devices available on the market today, which can serve as additional oral hygiene implements, among which we can highlight interproximal cleaning brushes and tongue cleaners. However, patient adherence to this routine seems to be the most difficult task. Studies show that only $10 \%$ of the population use dental floss/tape and interdental brushes regularly. ${ }^{28}$

Furthermore, studies show that proper oral care hygiene measures at home are key to maintaining dental implant stability and to preventing tissue inflammation and possible complications. ${ }^{29,30}$

Bacterial accumulation is associated with clinical signs of both tooth and implant inflammation. ${ }^{31}$ Accordingly, regular and complete biofilm elimination becomes essential for disease prevention and host protection.

\section{Chemical methods recommended for peri-implant biofilm control}

As in the precautions required for natural dentition, the prevention of biofilm formation and its elimination from the implant surface is the first step to treating peri-implant disease. Peri-implant mucositis therapy is based on non-surgical therapy with supra- and submucosal scaling, whether associated to antimicrobial agents or not, including chlorhexidine and essential oils..$^{32,33,34}$ However, not all antimicrobials can offer additional clinical benefits. Studies evaluating antimicrobial activities on periimplant biofilms are important because the biofilm formed on dental surfaces has different characteristics from that formed on a titanium surface. ${ }^{11,12}$

Gosau et al. ${ }^{35}$ evaluated biofilm reduction on titanium specimens affixed to removable dental appliances and found that antimicrobial substances, such as sodium hypochlorite, 3\% hydrogen peroxide, $0.2 \%$ chlorhexidine digluconate and essential oils, were able to reduce bacteria viability on the biofilm 
that developed on a titanium surface, as compared with saline solution. Likewise, $0.5 \%$ cetylpyridinium chloride and $40 \%$ citric acid were not effective in reducing biofilm.

Antimicrobial action on peri-implant biofilm was also demonstrated by Baffone et al. ${ }^{36}$ According to these authors, $0.2 \%$ chlorhexidine, essential oils, stannous fluoride and hexetidine associated with methylparaben and propylparaben were effective in reducing peri-implant biofilm in vitro. Among the antimicrobials evaluated, chlorhexidine and essential oils proved most effective in reducing biofilm under experimental conditions.

In a peri-implant induced disease model, Trejo et al. ${ }^{34}$ evaluated the adjuvant action of antimicrobials associated to mechanical treatments, and the results demonstrated effects similar to those of an unassociated mechanical treatment for 3 to $4 \mathrm{~mm}$ deep peri-implant mucositis pockets. In humans, chlorhexidine used in the form of an irrigation solution, ${ }^{37}$ gel $^{38}$ or chemical agent in a full-mouth disinfection approach ${ }^{22}$ also did not offer any additional clinical and/or microbiological benefits over the mechanical treatment alone.

Felo et al. $^{33}$ reported that when diluted $0.06 \%$ chlorhexidine is used in a powered irrigator, as compared to rinsing with $0.12 \%$ chlorhexidine gluconate once daily, it may be a valuable adjunct for oral health in patients with implants, in reducing plaque and gingivitis 3 months after initial prophylaxis; however, there was no mechanical treatment group in this study. The superior results of chlorhexidine irrigation, compared with chlorhexidine mouthrinse, in reducing plaque and marginal bleeding were also identified in a systematic review published by Grusovin et al. ${ }^{39}$

On the other hand Ciancio et al. ${ }^{32}$ demonstrated that essential oil mouthrinses used twice a day were effective in reducing plaque and marginal bleeding, as compared with placebo in dental implant patients on maintenance therapy. Mouthrinses containing essential oils were also statistically superior to placebo in reducing plaque and marginal bleeding, according to Grusovin et al..$^{39}$ Ramberg et al. ${ }^{40}$ confirmed that brushing with a toothpaste containing triclosan reduced gingival bleeding and pocket depth, compared with placebo dentifrice. These findings corroborate the conclusions by Renvert et al., ${ }^{21}$ i.e., that mechanical non-surgical therapy is not effective for peri-implant mucositis treatment, and its effects are boosted by particular chemical agents. Furthermore, according to these authors, mechanical treatment for peri-implantitis is limited, and chlorhexidine offers few additional benefits.

In addition to the active ingredients found in mouthrinses, there are those found in toothpastes. For example, toothpaste containing triclosan also showed clinical benefits when used to control periimplant biofilm. Moreover, $0.3 \%$ triclosan with a $2 \%$ copolymer formulation associated to sodium fluoride was more effective in controlling peri-implant mucosal biofilms and inflammation than toothpaste containing sodium fluoride alone. ${ }^{41,42}$

Figure 1 illustrates in what peri-implantitis clinical conditions antimicrobial agents can be incorporated in association with supra- and submucosal scaling.

\section{Active ingredients used for chemical biofilm control}

The most common therapeutic agents found in commercial mouthrinse brands include a combination of four essential oils (thymol, eucalyptol, menthol and methyl salicylate), ${ }^{43}$ hexetidine, chlorhexidine gluconate, ${ }^{44}$ benzalkonium chloride, cetylpyridinium chloride, hydrogen peroxide, and sometimes domiphen bromide, fluoride ${ }^{45}$ and $x y-$ litol. ${ }^{46}$ These rinses have often been tested as adjuvants for daily oral hygiene procedures, and at least two agents, particularly $0.12 \%$ chlorhexidine digluconate and essential oils, have demonstrated clinical efficacy in both inhibiting and reducing dental biofilm formation, as a way of diminishing periodontal and peri-implant disease severity. ${ }^{47,48}$

Chlorhexidine has been reported to reduce biofilm buildup in approximately $60 \%$ and gingivitis severity in $50 \%$ to $80 \%$ of cases, as shown by way of improvements in clinical parameters. ${ }^{49}$ It has been demonstrated that the use of a mouthrinse containing $0.12 \%$ chlorhexidine digluconate results in a significant decrease in total anaerobes, total aerobes, Streptococci and Actinomyces, after 


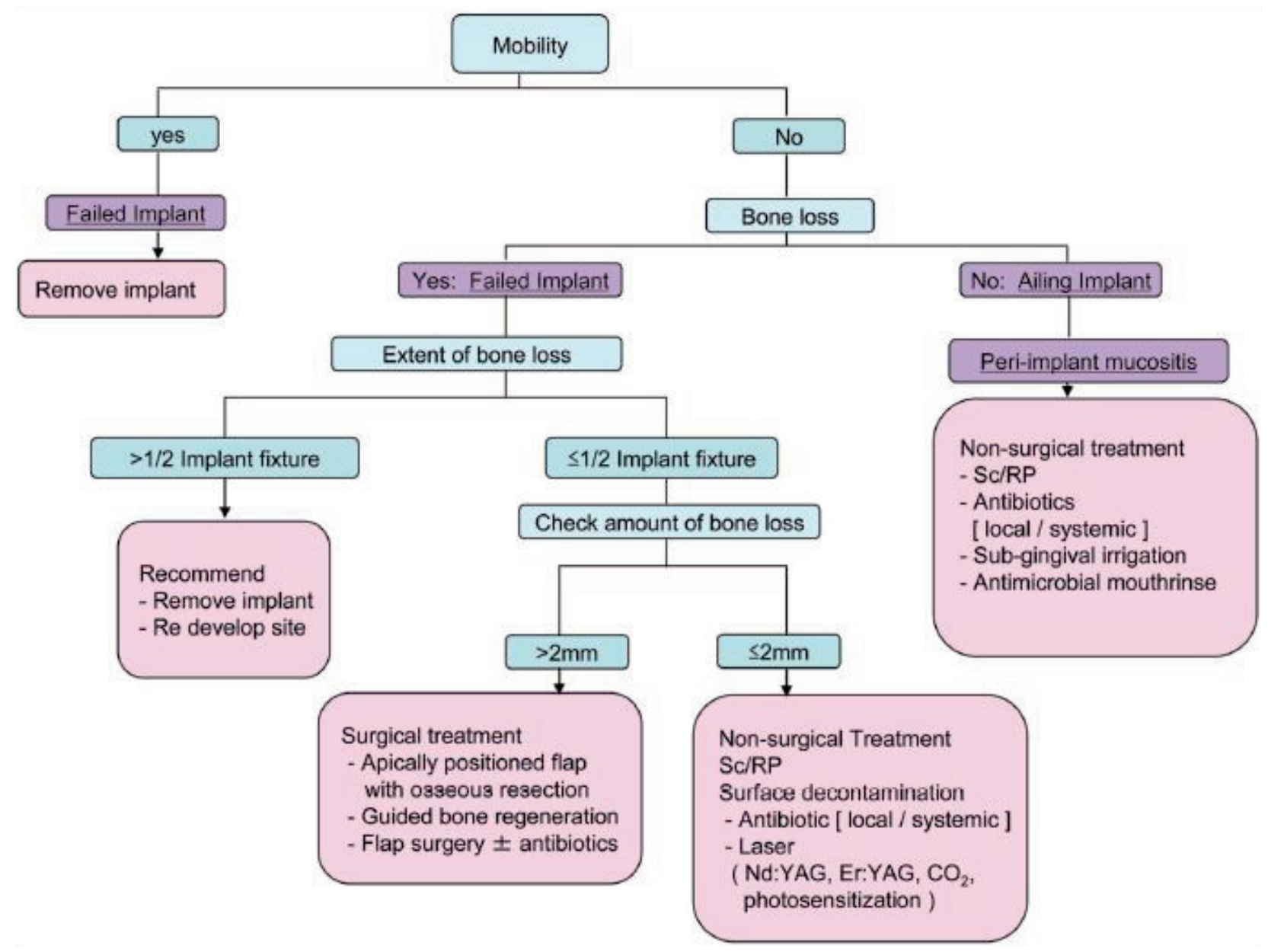

Figure 1 - Decision tree for the management of peri-implant diseases [Figure published in: Okayasu K, Wang LH. Decision tree for the management of peri-implant diseases. Implant Dent. 2012 Jun, 21 (3):253].

both three- and six-month periods. ${ }^{50}$ Nevertheless, essential oils delay biofilm development in $45 \%$ to $56 \%$ of cases and reduce the existing biofilm in $39 \%$ to $48 \%$ of cases, whereas a reduction of up to $59 \%$ in gingivitis is also observed after their continuous use. Studies have shown that essential oils have an effect on microbial total mass and promote an overall decrease in both biofilm activity and biomass. ${ }^{49,51,52,53,54}$ Essential oils also have some interesting and desirable features, such as reducing bacterial endotoxins and pathogenicity. ${ }^{55,56}$ They also promote deep biofilm penetration, which destroys more pathogenic resistant forms (lysis), ${ }^{51,52}$ have great clinical efficacy and deliver action that alters microorganism cell surface integrity. ${ }^{57}$ Other important features are their residual effect, derived from antibacterial activity that continues even after rinsing, ${ }^{58,59,60}$ and their ability to maintain oral microbiota balance by not allowing the emergence of opportunistic species. ${ }^{61}$

According to good clinical practices and systematic reviews, ${ }^{62,63}$ only two active ingredients, $0.12 \%$ chlorhexidine digluconate ${ }^{64}$ and essential oils, ${ }^{65,66}$ should be considered the most effective, since they have been thoroughly tested and proven as effective for decades, and are also the only ones carrying the ADA seal of approval. ${ }^{67,68}$ Moreover, $0.05 \%$ cetylpyridinium chloride and $0.03 \%$ triclosan active principles have been mentioned extensively in the literature, indicating their use in reducing plaque $(24 \%$ to $28.2 \%$ and $24 \%$ to $29.1 \%$ ) and gingivitis (24\% to $29.1 \%$ and $16.9 \%$ to $23 \%$, respectively); ${ }^{49}$ however, 
they have less significant results in comparison with chlorhexidine and essential oils.

\section{Unwanted side effects on dental implant surfaces}

Although not directly related to dental implants, mouthrinses with different active ingredients can lead to some unwanted effects. Long-term use of mouthrinses containing chlorhexidine has led to some undesirable effects, such as staining of dental restorations and soft tissues, changes in the sense of taste, an increase in supragingival dental calculus formation, ${ }^{69,70}$ mucosal erosions and some cases of parotid gland swelling, ${ }^{71,72,73}$ but it is important to mention that these effects disappear after cessation of use. Despite these local adverse effects, no systemic change has been observed in association with long-term chlorhexidine use. ${ }^{69,73}$ Unfortunately, this is not the case of triclosan, whether associated to Gantrez or not. In an in vivo investigation, Cherednichenko et al. ${ }^{74}$ suggested that triclosan weakens cardiac and skeletal muscle contractility in a manner that may negatively impact muscle health, especially in susceptible populations.

In regard to cetylpyridinium chloride, a quaternary ammonium compound, the following side effects have been reported in association with its use:

- burning sensation of oral mucosa, ${ }^{75}$

- tongue dorsum and dental staining similar to that of chlorhexidine, ${ }^{75}$ and

- recurrent ulceration similar to aphthae. ${ }^{76}$

Among other active ingredients associated with adverse effects, fluoride can corrode titanium dental implants and prosthetic components, ${ }^{77}$ and mouthrinses containing antibiotics are not cost-effective and have several side effects, such as causing chang-

\section{References}

1. Pontoriero R, Tonelli MP, Carnevale G, Mombelli A, Nyman SR, Lang NP. Experimentally induced peri-implant mucositis. A clinical study in humans. Clin Oral Implants Res. 1994 Dec;5(4):254-9.

2. Costerton JW. Introduction to biofilm. Int J Antimicrob Agents. 1999 May;11(3-4):217-21. es in the sense of taste, tooth and soft tissue staining, irritation, peri-implant mucositis, and bacterial resistance or opportunistic infection. ${ }^{78}$

\section{Conclusions}

It is known that gaps between a pillar and a dental implant are still inevitable. Gaps can facilitate bacterial microleakage, causing problems such as bad breath and peri-implantitis. ${ }^{79}$ The prevalence of peri-implant diseases is growing; therefore, effective prevention methods seem to be as important for implant recommendation as the improvement of professional training. Some conclusions may have been presented, but more scientific evidence is required to elucidate the most effective method for treating peri-implant diseases. Further research should include an analysis of the real impact of different adjuvant therapies, with their benefits and risks, the additional costs involved, the time required and the increase in the number of individuals with dental implants.

Based on this review, it can be concluded that:

- There is strong clinical evidence that at least two mouthrinses have proven efficacy against different oral biofilms, namely, chlorhexidine digluconate and essential oils.

- $0.12 \%$ chlorhexidine digluconate presents a number of unwanted side effects and should be prescribed with caution.

- Chemical agents seem to be beneficial in controlling peri-implant inflammation, but require further investigation.

- We recommend an antiseptic with scientifically proven efficacy, with a significant short- and long-term effect, and with no unwanted side effects, for the prevention and/or treatment of periimplant disease.
3. Lang NP, Wilson TG, Corbet EF. Biological complications with dental implants: their prevention, diagnosis and treatment. Clin Oral Implants Res. 2000;11 Suppl 1:146-55.

4. Socransky SS, Haffajee AD. Dental biofilms: difficult therapeutics targets. Periodontol 2000. 2002 Jan;28(1):12-55.

5. Botero J, González A, Mercado R, Olave G, Contreras A. Subgingival microbiota in peri-implant mucosa lesions and 
adjacent teeth in partially edentulous patients. J Periodontol. 2005 Sep;76(9):1490-5.

6. Cortelli SC, Cortelli JR, Romeiro RL, Costa FO, Aquino DR, Orzechowski PR, et al. Frequency of periodontal pathogens in equivalent peri-implant and periodontal clinical statuses. Arch Oral Biol. 2013 Jan;58(1):67-74.

7. Koyanagi T, Sakamoto M, Takeuchi Y, Ohkuma M, Izumi Y. Analysis of microbiota associated with Peri-implantitis using 16 rRNA gene clone library. J Oral Microbiol [Internet]. 2010 May 24 [cited 2013 Mar 10];2:10.3402/jom.v2i0.5104. Available from: http://www.ncbi.nlm.nih.gov/pmc/articles/ PMC3084566/.

8. Kumar OS, Mason MR, Brooker MR, O’Brien K. Pyrosequencing reveals unique microbial signatures associated with healthy and failing dental implants. J Clin Periodontol. 2012 May;39(5):425-33.

9. Koyanagi T, Sakamoto M, Takeuchi Y, Maruyama N, Ohkuma M, Izumi Y. Comprehensive microbiological findings in peri-implantitis and periodontitis. J Clin Periodontol. 2013 Mar;40(3):218-26.

10. Heitz-Mayfield LJ, Lang NP. Comparative biology of chronic and aggressive periodontitis vs. peri-implantitis. Periodontol 2000. 2010 Jun;53(1):167-81.

11. Grössner-Schreiber B, Teichmann J, Hanning M, Dörfer C, Wenderoth DF, Ott SJ. Modified implant surfaces show different biofilm compositions under in vivo conditions. Clin Oral Implants Res. 2009 Aug;20(8):817-26.

12. Rehman A, Hu J, Ott, SJ, Grössner-Schreiber B. Microbial Community Composition on Modified Dental Implant Surfaces: an in vivo study. Int J Oral Maxillofac Implants. 2012 JulAug;27(4):811-9.

13. Salvi GE, Agletta M, Eick S, Sculean A, Lang NP, Ramseier CA. Reversibility of experimental peri-implant mucositis comapared with experimental gingivitis in humans. Clin Oral Implants Res. 2012 Feb;23(2):182-90.

14. Lindhe J, Berglundh T, Ericsson I, Liljenberg B, Marinello C. Experimental breakdown of peri-implant and periodontal tissues. A study in the beagle dog. Clin Oral Implants Res. 1992 Mar;3(1):9-16.

15. Mombelli A, Müller N, Cionca N. The epidemiology of periimplantitis. Clin Oral Implants Res. 2012 Oct;23 Suppl 6:6776

16. Máximo MB, Mendonça AC, Alves JF, Cortelli SC, Peruzzo DC, Duarte PM. Peri-implant diseases may be associated with increased time loading and generalized periodontal bone loss: preliminary results. J Oral Implantol. 2008;34(5):268-73.

17. Costa FO, Takenaka-Martinez S, Cota LO, Ferreira SD, Silva GL, Costa JE. Peri-implant disease in subjects with and without preventive maintenance: a 5 -year follow-up. J Clin Periodontol. 2012 Feb;39(2):173-81.

18. Abreu MH, Bianchini MA, Magini RS, Rösing CK. Clinical and radiographic evaluation of periodontal and peri-implant conditions in patients with implant-supported prosthesis. Acta Odontol Latinoam. 2007;20(2):87-95.

19. Carter HG, Barnes GP, Radentz WH. The effects of using various types of dental floss on gingival sulcular bleeding. Va Dent J. 1975 Feb;42:18-27.

20. Bergenholtz A, Brithon J. Plaque removal by dental floss or tooth pick. An intraindividual comparative study. J Clin Periodontol. 1980 Dec;7(6):516-24.

21. Renvert S, Roos-Jansaker AM, Claffey N. Non-surgical treatment of peri-Implant mucositis and peri-implantitis: a literature review. J Clin Periodontol. 2008 Sep;35 Suppl. 8:305-15.

22. Thöne-Mühling M, Swierkot K, Nonnenmacher C, Mutters R, Flores-de-Jacoby L, Mengel R. Comparison of two full-mouth approaches in the treatment of peri-implant mucositis: a pilot study. Clin Oral Implants Res. 2010 May;21(5):504-12.

23. Thierbach R, Eger T. Clinical outcome of a nonsurgical and surgical treatment protocol in different types of peri-implantitis: a case series. Quintessence Int. 2013 Feb;44(2):137-48.

24. Leonhardt A, Gröndahl K, Bergström C, Lekholm U. Longterm follow up of osseointegrated titanium implants using clinical, radiographic and microbiological parameters. Clin Oral Implants Res. 2002 Apr;13(2):127-32.

25. Lang NP, Berglundh T, Working group 4 of seventh European Workshop on Periodontology. Periimplant diseases: where are we now?. Consensus of the Seventh European Workshop on Periodontology. J. Clin Periodontol. 2011 Mar;38 Suppl 11:178-81.

26. Bass CC. An effective method of personal oral hygiene. J La State Med Soc. 1954 Feb;106(2):57-73.

27. Caton JG, Blieden TM, Lowenguth RA, Frantz BJ, Wagener CJ, Doblin JM, et al. Comparison between mechanical cleaning and an antimicrobial rinse for the treatment and prevention of interdental gingivitis. J Cli Periodontol. 1993 Mar;20(3):172-8.

28. Kalsbeek H, Truin GJ, Poorterman JH, VanRossum GM, Van Rijkom HM, Verrips GH. Trends in periodontal status and oral hygiene habbits in Dutch adults between 1983 and 1995. Community Dent Oral Epidemiol. 2000 Apr;28(2):112-8.

29. Silverstein LH, Kurtzmian GM. Oral hygiene and maintenance of dental implants. Dent Today. 2006 Mar;25(3):70-5.

30. Serino G, Ström C. Peri-implantitis in partially edentulous patients: associations with inadequate plaque control. Clin Oral Implants Res. 2009 Feb;20(2):169-74.

31. Zitzmann NU, Berglundh T, Marinello CP, Lindhe J. Experimental peri-implant mucositis in man. J. Clin Periodontol. 2001 Jun;28(6):517-23.

32. Ciancio F, Lauciello O, Shibly M, Vitello MM. The effect of an antiseptic mouthrinse on implant maintenance: plaque and peri-implant gingival tissues. J Periodontol. 1995 Nov;66(11):962-5.

33. Felo A, Shibly O, Ciancio SG, Lauciello FR, Ho A. Effects of subgingival chlorhexidine irrigation on peri-implant maintenance. Am J Dent. 1997 Apr;10(2):107-10. 
34. Trejo PM, Bonaventura G, Weng D, Caffesse RG, Bragger U, Lang NP. Effect of mechanical and antiseptic therapy on peri-implant mucositis: an experimental study in monkeys. Clin Oral Implants Res. 2006 Jun;17(3)294-304.

35. Gosau M, Hahnel S, Schwarz F, Gerlach T, Reichert TE, Bürgers R . Effect of six different peri-implantitis disinfection methods on in vivo human oral biofilm. Clin Oral Implants Res. 2010 Aug;21(8):866-72.

36. Baffone W, Sorgente G, Campana R, Patrone V, Sisti D, Falcioni T. Comparative effect of chlorhexidine and some mouthrinses on bacterial biofilm formation on titanium surface. Curr Microbiol. 2011 Feb;62(2):445-51.

37. Porras R, Anderson GB, Caffesse RG, Narendran S, Trejo PM. Clinical response to 2 different therapeutic regimens to treat peri-implant mucositis. J Periodontol. 2002 Oct;73(10);111825.

38. Heitz-Mayfield LJ, Salvi GE, Botticelli D, Mombelli A, Faddy M, Lang NP, Implant complication research group. Anti-infective treatment of peri-implant mucositis: a randomized controlled clinical trial. Clin Oral Implants Res. 2011 Mar;22(3):237-41.

39. Grusovin MG, Coulthard P, Worthington HV, George P, Esposito M. Interventions for replacing missing teeth: maintaining and recovering soft tissue health around dental implants. Cochrane Database Syst Rev. 2010 Aug 4;(8):CD003069.

40. Ramberg P, Lindhe J, Botticelli D, Botticelli A. The effect of a triclosan dentifrice on mucositis in subjects with dental implants: a six-month clinical study. J Clin Dent. 2009;20(3):1037.

41. Sreenivasan PK, Vered Y, Zini A, Mann J, Kolog H, Steinberg D, et al. A 6-month study of the effects of $0.3 \%$ triclosan/ copolymer dentifrice on dental implants. J Clin Periodontol. $2011 \mathrm{Jan} ; 38(1): 33-42$.

42. Trombelli L, Farina R. Efficacy of triclosan-based toothpastes in the prevention and treatment of plaque-induced periodontal and peri-implant diseases. Minerva Stomatol. 2013 Mar;62(3):71-88.

43. Stoeken JE, Paraskevas S, Van der Weijden GA. The longterm effect of a mouthrinse containing essential oils on dental plaque and gingivitis: a systematic review. J Periodontol. 2007 Jul;78(7):1218-28.

44. Ribeiro LG, Hashizume LN, Maltz M. The effect of different formulations of chlorhexidine in reducing levels of mutans streptococci in the oral cavity: A systematic review of the literature. J Dent. 2007 May;35(5):359-70.

45. Hasturk H, Nunn M, Warbington M, Van Dyke TE. Efficacy of a fluoridated hydrogen peroxide-based mouthrinse for the treatment of gingivitis: a randomized clinical trial. J Periodontol. 2004 Jan;75(1):57-65.

46. Lif Holgerson P, Stecksén-Blicks C, Sjöström I, Oberg M, Twetman S. Xylitol concentration in saliva and dental plaque after use of various xylitol-containing products. Caries Res. 2006;40(5):393-7.
47. Kozlovsky A, Tal H, Laufer B-Z, Leshem R, Rohrer MD, Weinreb $\mathrm{M}$, et al. Impact of implant overloading on the periimplant bone in inflamed and non-inflamed peri-implant mucosa. Clin Oral Implants Res. 2007 Oct;18(5):601-10.

48. Alissa R, Oliver RJ. Influence of prognostic risk indicators on osseointegrated dental implant failure: a matched case-control analysis. J Oral Implanton. 2012 Feb;38(1):51-61.

49. Barnett ML. The role of therapeutic antimicrobial mouthrinses in clinical practice: control of supragingival plaque and gingivitis. J Am Dent Assoc. 2003 Jun;134(6):699-704.

50. Budtz-Jörgensen E, Löe H. Chlorhexidine as a denture disinfectant in the treatment of denture stomatitis. Scand J Dent Res. 1972;80(6):457-64.

51. Pan P, Barnett ML, Coelho J, Brogdon C, Finnegan MB. Determination of the in situ bactericidal activity of an essential oil mouthrinse using a vital stain method. J Clin Periodontol. 2000 Apr;27(4):256-61.

52. Fine DH, Furgang D, Barnett ML. Comparative antimicrobial activities of antiseptic mouthrinses against isogenic planktonic and biofilm forms of Actinobacillus actinomycetemcomitans. J Clin Periodontol. 2001 Jul;28(7):697-700.

53. Sharma NC, Charles CH, Qaqish JG, Galustians HJ, Zhao Q, Kumar LD. Comparative effectiveness of an essential oil mouthrinse and dental floss in controlling interproximal gingivitis and plaque. Am J of Dent. 2002 Dec;15(6):351-5.

54. Gunsolley JC. A meta-analysis of six-month studies of antiplaque and antigingivitis agents. J Am Dent Assoc. 2006 Dec;137(12):1649-57.

55. Fine DH, Letizia J, Mandel ID. The effect of rinsing with Listerine antiseptic on the properties of developing dental plaque. J Clin Periodontol. 1985 Sep;12(8):660-6.

56. Fine DH, Furgang D, Lieb R, Korik I, Vincent JW, Barnett ML. Effects of sublethal exposure to an antiseptic mouthrinse on representative plaque bacteria. J Clin Periodontol. 1996 May;23(5):444-51.

57. Kubert D, Rubin M, Barnett ML, Vincent JW. Antiseptic mouthrinse-induced microbial cell surface alterations. Am J Dent. 1993 Dec;6(6):277-9.

58. Pitts G, Brogdon C, Hu L, Masurat T, Pianotti R, Schumann P. Mechanism of action of an antiseptic, anti-odor mouthwash. J Dent Res. 1983 Jun;62(6):738-42.

59. Ross NM, Charles CH, Dills SS. Long-term effects of Listerine antiseptic on dental plaque and gingivitis. J Clin Dent. 1989;1(4):92-5.

60. Jenkins S, Addy M, Wade W, Newcombe RG. The magnitude and duration of the effects of some mouthrinse products on salivary bacterial counts. J Clin Periodontol. 1994 Jul;21(6):397401.

61. Minah GE, DePaola LG, Overholser CD, Meiller TF, Niehaus C, Lamm RA, et al. Effects of 6 months use of an antiseptic mouthrinse on supragingival dental plaque microflora. J Clin Periodontol. 1989 Jul;16(6):347-52. 
62. Gunsolley JC. Clinical efficacy of antimicrobial mouthrinses. J Dent. 2010 Jun;38 Suppl 1:S6-10.

63. Neely AL. Essential oil mouthwash (EOMW) may be equivalent to chlorhexidine (CHX) for long-term control of gingival inflammation but CHX appears to perform better than EOMW in plaque control. J Evid Based Dent Pract. 2012 Sep;12 Suppl 3:69-72.

64. Overholser CD, Meiller TF, DePaola LG, Minah GE, Niehaus C. Comparative effects of 2 chemotherapeutic mouthrinses on the development of supragingival dental plaque and gingivitis. J Clin Periodontol. 1990 Sep;17(8):575-9.

65. Lamster IB, Alfano MC, Gordon JM. The effect of Listerine antiseptic on reduction of existing plaque and gingivitis. Clin Prev Dent. 1983;5:12-6.66. Charles CH, Sharma NC, Galustians HJ, Qaqish J, McGuire JA, Vincent JW. Comparative efficacy of an antiseptic mouthrinse and an antiplaque/ antigingivitis dentifrice: a six-month clinical trial. J Am Dent Assoc. 2001 May;132(5):670-5.

67. Council on Dental Therapeutics. Guidelines for acceptance of chemotherapeutics products for the control of supragingival dental plaque and gingivitis. J Am Dent Assoc. 1986 Apr;112(4):529-32.

68. Fedorowicz Z, Aljufairi H, Nasser M, Outhouse TL, Pedrazzi V. Mouthrinses for the treatment of halitosis. Cochrane Database Syst Rev. 2008 Oct;4:1-23.

69. Addy M. Chlorhexidine compared with other locally delivered antimicrobials. A short review. J Clin Periodontol. 1986 Nov;13(10):957-64.

70. Flötra L, Gjermo P, Rölla G, Waerhaug J. Side effects of chlorhexidine mouth washes. Scand J Dent Res. 1971;79(2):119-25.
71. Löe H, Schiott CR. The effect of mouthrinses and topical application of chlorhexidine on the development of dental plaque and gingivitis in man. J Periodontal Res. 1970;5(2):79-83.

72. Eriksen HM, Nordbo H, Kantanen H, Ellingsen JE. Chemical plaque control and extrinsic tooth discoloration. A review of possible mechanisms. J Clin Periodontol. 1985 May;12(5):34550.

73. Gagari E, Kabani S. Adverse effects of mouthwash use. A review. Oral Surg Oral Med Oral Pathol Oral Radiol Endod. 1995 Oct;80(4):432-9.

74. Cherednichenko G, Zhang R, Bannister RA, Timofeyev V, Li $\mathrm{N}$, Fritsch EB, et al. Triclosan impairs excitation-contraction coupling and $\mathrm{Ca} 2+$ dynamics in striated muscle. Proc Natl Acad Sci U S A. 2012 Aug;109(35):14158-63.

75. Bonesvoll P, Gjermo P. A comparison between chlorhexidine and some quaternary ammonium compounds with regard to retention, salivary concentration and plaque-inhibiting effect in the human mouth after mouth rinses. Arch Oral Biol. 1978;23(4):289-94.

76. Ashley FP, Skinner A, Jackson PY, Wilson RF. Effect of a $0.1 \%$ cetylpyridinium chloride mouthrinse on the accumulation and biochemical composition of dental plaque in young adults. Caries Res. 1984;18(5):465-71.

77. Robin A, Meirelis JP. Influence of fluoride concentration and $\mathrm{pH}$ on corrosion behavior of titanium in artificial saliva. $\mathrm{J}$ Appl Electrochem. 2007;37(4):511-7.

78. Stewart PS, Costerton JW. Antibiotic resistance of bacteria in biofilms. Lancet. 2001 Jul 14;358(9276):135-8.

79. Teixeira W, Ribeiro RF, Sato S, Pedrazzi V. Microleakage into and from two-stage implants: an in vitro comparative study. Int J Oral Maxillofac Implants. 2011 Jan-Feb;26(1):56-62. 


\section{ERRATUM}

In article "Antimicrobial mouthrinse use as an adjunct method in peri-implant biofilm control", DOI: 10.1590/1807-3107BOR-2014.vol28.0022; Braz Oral Res., (São Paulo) 2014;28(Spec Iss 1), where it reads:

Declaration of Interests: The authors certify that they have no commercial or associative interest that represents a conflict of interest in connection with the manuscript.

It should read:

Declaration of Interests: The authors have received support from Johnson \& Johnson (J \& J) for writing this review. 